Proceedings

\title{
Relationships Between Urban Form and Mobility: Gender and Mode of Transport
}

\author{
Iveth Rodríguez De La Rosa ${ }^{1 *}$, Eric Gielen², and José-Sergio Palencia-Jiménez ${ }^{2}$ \\ 1 Transport and Society Chair. Universitat Politècnica de València (Spain) \\ 2 Urbanism Department. Universitat Politècnica de València (Spain) \\ * Correspondence: i-veth05@hotmail.com
}

Abstract: With the growth of urban areas, cities are the centres of the great challenges of our society. Urban form influences the metabolism of cities in multiple ways and mobility is one of them. Depending on the type of urban fabric, population, and activities located in them, travel needs and modes of transport differences appear. As population is diverse, this relationship between urban form and mobility probably has significant gender gaps that should be investigated. The aim of this paper is to demonstrate the correlation between the type of urban fabric and people's mobility patterns, looking for significant gender differences in the number of trips and the mode of transport. Data were collected from the survey done for the Mobility Plan of the Metropolitan Area of Valencia and cadastral information. For statistical analysis, the PSPP program and Pearson's correlation coefficient were used. This paper demonstrates significant differences in relation to gender and modes of transport. Women use more sustainable modes of transport, especially in dense and compact cities. Urban sprawl increases mobility, especially trips using private motorised modes. On the contrary, more sustainable modes, like by foot, on bike, or using public transport, are used in compact cities. Looking for sustainable mobility, women and density are key aspects which land planners must take into account when designing cities.

Keywords: Gender; Urban Form; Mobility; Urban Sprawl; City; Valencia Metropolitan Area

Citation: Rodríguez De La Rosa, I.; Gielen, E.; Palencia-Jiménez, J.S., 2022, Relationships Between Urban Form and Mobility: Gender and Mode of Transport. SUPTM 2022 conference proceedings sciforum-052024. https://doi.org/10.31428/10317/10584

Publisher's Note: UPCT and Sciforum stays neutral with regard to jurisdictional claims in published maps and institutional affiliations.

Copyright: (c) 2022 by the authors. Submitted for possible open access publication under the terms and conditions of the Creative Commons Attribution (CC BY) license (https://creativecommons.org/license s/by/4.0/).

\section{Introduction}

Urban populations will account for almost 70\% of the world's population by 2050 [1] so SDG compliance must be found in cities. Furthermore, the development of cities shows a process of urban expansion known as urban sprawl [2]. This phenomenon, characterised by low urban densities and longer distances between urban fabrics [3], has social, economic, and environmental effects [4-8], but it is not entirely clear how it affects mobility. Travel distance and car use for commuting in the city outskirts have increased due to urban sprawl $[9,10]$. However, some, such as [11], argue that upward mobility is significantly higher in compact than in large areas. They attribute it to better job accessibility in more compact areas. Others argue that it depends on the scale of the study [12] and the territorial context [13].

Changes as a consequence of the expansion of the dispersed territorial model and new lifestyles affect different population groups differently [14]. Cities are not genderneutral and therefore offer important opportunities to narrow the gender gap and reduce inequalities [15]. The inclusion of a gender perspective in urban planning and mobility studies is a priority issue [16,17]. Analysing cities from a gender perspective involves considering the importance of gender roles [18]. According to [19], women carry out multi-purpose activities and perform several tasks in the same trip, which are conditioned by the transport model. Similarly, [20] argues that gender differences in mobility are due to physical and social factors rooted in the cultural idiosyncrasies of the territory. Mobility in cities is a complex and multidimensional issue [21]. Gender is one of the factors 
conditioning mobility [13-15, 18, 20, 22, 23]. However, there is little literature on analysing 1 the effect of urban form on this mobility.

The objective is to determine the influence of urban form on people's mobility in general and by gender, analysing differences in reasons for travel and mode of transport. The aim is to see if there are significant differences in mobility patterns by gender according to the city's urban form. First, the urban structure of the city is defined on the basis of urban form indicators such as density, surface area, and diversity. Second, the mobility and socio-demographic characteristics of the people in the city are studied. Finally, a correlation is made between the type of urban fabric and the mobility patterns identified.

\section{Methods}

The study area corresponds to the Metropolitan Area of Valencia (AMV) on the Mediterranean coast of the Iberian Peninsula. It has 71 municipalities and around 1.9 million people. It covers an area of $2,133.1 \mathrm{~km}^{2}$ and has a population density of 887 inhabitants per $\mathrm{km}^{2}$. In the AMV, almost five million trips are made every day [24]. The central part of the AMV has dense and compact urban fabrics, while the more peripheral areas correspond to more dispersed urban areas [25].

Data from the Basic Mobility Plan for the Valencia Metropolitan Area (PMOME) were used [24]. The survey of 18,444 households, equivalent to 50,233 people, was analysed. The survey provides data on individuals (gender, age, household characteristics, income, number of vehicles, etc.) and trips (reason for trip, point of origin and destination, mode of transport, duration, etc.). Then the map of transport zones defined according to administrative, land use, and population criteria was used. The proposed zoning identifies 560 transport zones. Data on buildings from the INSPIRE service of the Cadastral Cartography of the General Directorate of the Cadastre of the Spanish Government were also used. Two urban form indicators were calculated for each Transport Zone (TZ):

Density $=$ Residential roof area $\left(\mathrm{m}^{2}\right) / \mathrm{TZ}$ area (hectares)

Area $=$ Residential roof area $\left(\mathrm{m}^{2}\right) /$ number of residential buildings

The following variables were then obtained: Sum of trips; Sum of trips by sustainable modes (walking and cycling); Sum of motorised trips (car, motorbike, and taxi); Sum of public transport trips (bus, subway, and train). All of them were calculated by TZ, in total, and by gender. Next, a bivariate correlation analysis (Pearson) was carried out with the PSPP statistical programme between the different variables characteristic of mobility (dependant) and characteristic of the urban form (independent). Pearson's correlation coefficients $(\mathrm{R})$ and their significance $(p)$ were obtained. $p \leq 0.05$ was significant so the correlation coefficients were interpreted as follows: $0.4 \leq \mathrm{R}<0.7$, medium high positive correlation; $0 \leq \mathrm{R}<0.4$, medium low positive correlation; $0.4 \leq \mathrm{R}<0$, medium low negative correlation; $0.7 \leq \mathrm{R}<-0.4$, medium high negative correlation.

\section{Results}

Figure 1 shows that the city of Valencia has a higher intensity of residential use. The compact historic urban cores of the different municipalities of the metropolitan area are identified in contrast to the adjoining transport zones in numerous municipalities around Valencia where there is a lower density associated with the existing urban sprawl [25]. Table 1 shows the correlation results showing the effect of the form indicators on total trips and by gender. There is a positive correlation between density and number of trips, which is in agreement with [11]. Analysing the results by mode, the correlation is negative for motorised modes and positive for more sustainable modes and public transport. There are therefore more trips, but higher densities favour the use of more sustainable modes of public transport. Comparing the effect on gender, we find significant differences between women and men: in the case of women, bicycle, taxi, and bus use is higher, and the use of motorised modes lower. In terms of the size of buildings, which are larger in urban centres, there are also significant correlations showing more trips, greater use of sustainable 
modes of transport and public transport, with gender differences in the use of bicycles, 1 motorbikes, and taxis, with an increase in the use of these modes of transport by women in urban centres.

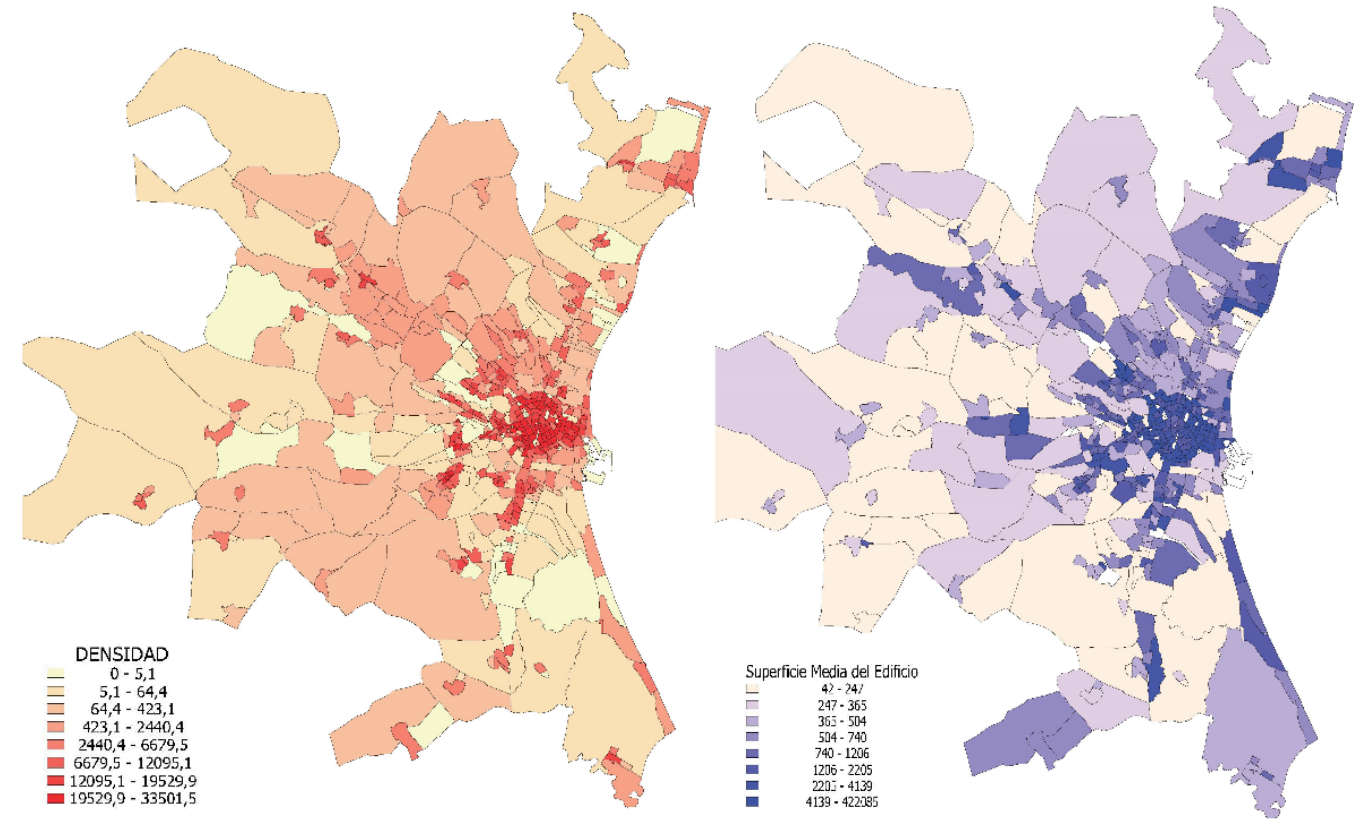

Figure 1. Residential density $\left(\mathrm{m}^{2} / \mathrm{ha}\right)$ and floor area of buildings $\left(\mathrm{m}^{2}\right)$

Table 1: Correlation between urban form variables and trips.

\begin{tabular}{|c|c|c|c|c|c|c|}
\hline \multirow{2}{*}{ Variable } & \multicolumn{3}{|c|}{ Density } & \multicolumn{3}{|c|}{ Area } \\
\hline & $\mathrm{R}$ & $p$ & & $\mathrm{R}$ & $p$ & \\
\hline Total trips & $\underline{0.30}$ & 0.00 & * & $\underline{0.14}$ & 0.01 & * \\
\hline$\%$ trip by $\mathrm{W} / \mathrm{M}$ & -0.04 & 0.49 & & -0.02 & 0.72 & \\
\hline Total motorised trips & $\underline{-0.38}$ & 0.00 & * & -0.07 & 0.21 & \\
\hline$\%$ motorised trips by $\mathrm{W} / \mathrm{M}$ & $\underline{-0.11}$ & 0.05 & * & -0.03 & 0.52 & \\
\hline Total sustainable trips & $\overline{0.54}$ & 0.00 & * & $\underline{0.11}$ & 0.05 & * \\
\hline$\%$ sustainable trips by $\mathrm{W} / \mathrm{M}$ & -0.09 & 0.08 & & 0.05 & 0.37 & \\
\hline Total public transport trips & $\underline{0.55}$ & 0.00 & * & $\underline{0.32}$ & 0.00 & * \\
\hline$\%$ public transport trips by $\mathrm{W} / \mathrm{M}$ & $\overline{-0.02}$ & 0.76 & & $\overline{-0.02}$ & 0.21 & \\
\hline$\%$ trip by car by $\mathrm{W} / \mathrm{M}$ & -0.06 & 0.24 & & -0.02 & 0.79 & \\
\hline$\%$ trip by motorbike by $\mathrm{W} / \mathrm{M}$ & 0.01 & 0.85 & & $\underline{0.11}$ & 0.05 & * \\
\hline$\%$ trip by bicycle by $\mathrm{W} / \mathrm{M}$ & $\underline{0.21}$ & 0.00 & * & $\overline{0.12}$ & 0.03 & * \\
\hline$\%$ trip in taxi by $\mathrm{W} / \mathrm{M}$ & $\underline{0.20}$ & 0.00 & * & $\underline{0.12}$ & 0.03 & * \\
\hline$\%$ trip by bus by W / M & 0.31 & 0.00 & * & 0.09 & 0.12 & \\
\hline$\%$ trip by train/subway by W / M & 0.01 & 0.83 & & -0.01 & 0.82 & \\
\hline
\end{tabular}

$\mathrm{W}=$ Female; $\mathrm{M}=$ Male; $^{*}=$ Significant

\section{Conclusions}

With this paper, it has been possible to show the influence that the shape of the city has on mobility, highlighting significant differences by mode of transport and gender. The disperse city, associated with lower densities, does not increase total trips, but it does increase trips by private motorised modes of transport to the detriment of the more sustainable modes of walking, cycling, and public transport. In addition, the higher proportion of sustainable modes of travel in urban centres has a clear gender component, as women are more likely to change their mode of transport than men, leaving the motor vehicle behind when they have alternatives to travel by more sustainable modes, such as walking, the bus, or the subway.

Author Contributions: All authors have read and agreed to the published version of the manuscript. Funding: This research was funded by Cátedra Transporte y Sociedad out of the Universitat 
Politècnica de València. Conflicts of Interest: The authors declare no conflicts of interest. The funders had no role in the design of the study; in the collection, analyses, or interpretation of data; in the writing of the manuscript, or in the decision to publish the results.

\section{References}

1. United Nations (2018). World Urbanization Prospects: The 2018 Revision. 123 p. https://doi.org/10.18356/b9e995fe-en

2. European Environment Agency (EEA) (2016). Urban sprawl in Europe. Joint EEA-FOEN report, EEA Report No 11/2016. Copenhagen: EEA.

3. Gielen, E.; Riutort-Mayol, G.; Palencia Jiménez, JS.; Cantarino-Martí, I. (2017). An urban sprawl index based on multivariate and Bayesian factor analysis with application at the municipality level in Valencia. Environment and Planning B Planning and Design. 1-27. doi:10.1177/2399808317690148

4. Real Estate Research Corporation (RERC) (1974) The Cost of Sprawl, Environment and Economic Costs of Alternative Residential Development Patterns at the Urban Fringe. Washington, DC: U.S. Government Printing Office, p. 278.

5. Speir, C, Stephenson, K (2002) Does sprawl cost us all? Journal of the American Planning Association 68(1): 56-70.

6. Garbiñe, H (2007) Los costes económicos y sociales de la ciudad de baja densidad. In: Indovina, F. (Coord.) La ciudad de baja densidad, lógicas y contención. Diputación Provincial de Barcelona, pp. 203-240.

7. Ewing, R (2008) Characteristics, causes, and effects of sprawl: A literature review. In: Marzluff JM et al. (eds) Urban Ecology. Boston: Springer, MA, pp. 519-535.

8. Gielen E, Riutort-Mayol G, Miralles i Garcia JL, Palencia Jiménez JS. Cost assessment of urban sprawl on municipal services using hierarchical regression. Environment and Planning B: Urban Analytics and City Science. 2021;48(2):280-297. doi:10.1177/2399808319869345

9. Pengjun Zhao (2010) Sustainable urban expansion and transportation in a growing megacity: Consequences of urban sprawl for mobility on the urban fringe of Beijing, Habitat International, Volume 34, Issue 2, 2010, Pages 236-243, https://doi.org/10.1016/j.habitatint.2009.09.008.

10. Aón L., Luciana Giglio M., Agustín Cola C. (2017) Patrones modales de movilidad y desarrollo urbano no planificado en la ciudad de La Plata. Transporte y Territorio, №. 17, 2017, págs. 117-144

11. Ewing R., Hamidi S., Grace JB, Yehua Dennis Wei (2016) Does urban sprawl hold down upward mobility?, Landscape and Urban Planning, Volume 148, 2016, Pages 80-88, https://doi.org/10.1016/j.landurbplan.2015.11.012.

12. Cebollada, A. y Miralles, C. (2003) Hábitos y percepciones de la movilidad cotidiana de las personas sin permiso de conducir. En J. Seguí (edit): Los servicios, los transportes y las redes territoriales. Universitat de les Illes Balears; Asociación de Geógrafos Españoles (AGE), Grupo de Geografía de los Servicios, Palma de Mallorca.

13. Hanson, S. (2010) Gender and mobility: new approaches for informing sustainability. Gender, Place \&Culture, 17, 5-23

14. Rodríguez Moya, J. M., \& García Palomares, J. C. (2012). Diversidad de género en la movilidad cotidiana en la Comunidad de Madrid. Boletín de la Asociación de Geógrafos Españoles, 58. https://doi.org/10.21138/bage.2061

15. Gauvin, L., Tizzoni, M., Piaggesi, S., Young, A., Adler, N., Verhulst, S., Ferres, L., \& Cattuto, C. (2020). Gender gaps in urban mobility. Humanities and Social Sciences Communications, 7(1), 1-13. https://doi.org/10.1057/s41599-020-0500-x

16. Novella Abril, Inés. 2017. «Género y planificación Urbana en la construcción de la Agenda Internacional para el Desarrollo Sostenible. de Estocolmo 1972 a Quito 2016». Kult-Ur 4 (8), 93-114. https://doi.org/10.6035/Kult-ur.2017.4.8.3.

17. Terraza, H.; Orlando, M.B.; Lakovits, C.; Lopes Janik, V.; Kalashyan, A. (2020). Handbook for Gender-Inclusive Urban Planning and Design. World Bank, Washington

18. Polk M., (2004):«The influence of gender on daily car use and on willingness to reduce car use in Sweden». Journal of Transport Geography, 12, 185-195.

19. Brown D, McGranahan G, Dodman D (2014) Urban informality and building a more inclusive, resilient and green economic. IIED, London

20. Rosenbloom S (2004) Understanding women's and men's travel patterns. In Research on Women's Issues in Transportation: Report of a Conference.

21. Vaitla B, Bosco C, Alegana V, Bird T, Pezzulo C, Hornby G, Sorichetta A, Steele J, Ruktanonchai C, Ruktanonchai N, Wetter E, Bengtsson L, Tatem AJ, Di Clemente R, Luengo-Oroz M, González MC, Nielsen R, Baar T, Vacarelu F, de Choudhury M, Sharma S, Logar T, Eekhout W (2017) Big Data and the Well-being of Women and Girls: Applications on the Social Scientific Frontier. Technical Report. Data2X

22. Chant S (2013) Cities through a "gender lens": a golden "urban age" for women in the global South? Environ Urban 25(1):929

23. Miralles-Guasch C., Martínez Melo M, Marquet O. (2016) A gender analysis of everyday mobility in urban and rural territories: from challenges to sustainability, Gender, Place \& Culture, 23:3, 398-417, DOI: 10.1080/0966369X.2015.1013448

24. Generalitat Valenciana (2018) Pla Bàsic de Mobilitat de l'Àrea Metropolitana de València. https://www.pmomevalencia.com/documents

25. Gielen, E., Garcia, J.L.M.I., Mayol, G.R. (2018). Multidimensional characterization of the regional urban model and the urban sprawl in Valencia. International Journal of Sustainable Development and Planning, Vol. 13, No. 4, pp. 493-505. https://doi.org/10.2495/SDP-V13-N4-493-505 